\title{
Latitudinal variation of ionospheric TEC at Northern Hemispheric region
}

\author{
Mahesh Parwani $^{1}$, Roshni Atulkar ${ }^{2}$, Shweta Mukherjee ${ }^{3}$, and P. K. Purohit ${ }^{2}$ \\ Received 20 June 2018; accepted 29 August 2018; published 15 February 2019.
}

This paper includes the study of diurnal, monthly, annual and seasonal variation of total electron content (TEC) at low, mid and high latitude in the Northern Hemispheric region. We have also correlated the TEC variation with the solar proxies (viz. Dst, $K p$ index, F10.7 cm and sunspot number). This study was carried out during low solar activity period of 24th solar cycle i.e. from January 2016 to December 2016, at the three latitudes namely Mangilao, US (GUUG) at $13.44^{\circ} \mathrm{N}, 144.80^{\circ} \mathrm{E}$, Urumqi, China (URUM) at $43.82^{\circ} \mathrm{N}, 87.60^{\circ} \mathrm{E}$, and $\mathrm{Ny}$-Alesund, Norway (NYAL) at $78.92^{\circ} \mathrm{N}$, $11.86^{\circ} \mathrm{E}$. We observed some unique feature like sinusoidal pattern of diurnal TEC and semiannual oscillation of seasonal TEC. We also observed that the highest values of diurnal and monthly TEC were obtained at low latitude station GUUG Mangilao. It is also seen that maximum seasonal TEC at low, mid and high latitudes was obtained during equinox. KEYWORDS: Ionospheric TEC; $D s t$; sunspot number; $K p$ index.

Citation: Parwani, Mahesh, Roshni Atulkar, Shweta Mukherjee, and P. K. Purohit (2019), Latitudinal variation of ionospheric TEC at Northern Hemispheric region, Russ. J. Earth. Sci., 19, ES1003, doi:10.2205/2018ES000644.

\section{Introduction}

Latitudinal variation is one of the most significant factors that affect ionospheric total electron content (TEC). It is related to the location of the subsolar point and peculiarities in dynamical processes of the upper atmosphere of the Earth [Klimenko et al., 2016]. The largest magnitude of solar energy is absorbed in low latitude $\left( \pm 30^{\circ}\right)$ in both hemispheres [Abdu et al., 1995]. This leads to higher ionization in this region. Therefore the low latitude region exhibits a number of unique phenomena, such as equatorial electrojet (EEJ),

\footnotetext{
${ }^{1}$ Department of Physics, Barkatullah University, Bhopal, India

${ }^{2}$ National Institute of Technical Teachers' Training \& Research, Bhopal, India

${ }^{3}$ VIT Bhopal University, Bhopal, India
}

Copyright 2019 by the Geophysical Center RAS. http://rjes.wdcb.ru/doi/2018ES000644-res.html equatorial ionization anomaly (EIA), plasma fountain, equatorial wind and temperature anomaly etc. [Jayachandran et al., 1997]. The equatorial ionosphere being highly variable posses serious threats to communication and navigation systems [Akala et al., 2010, 2011, 2012. The mid-latitude ionosphere is a relatively less variable region, therefore, most of the ionospheric observations and measurements are obtained in this region [Akala et al., 2013a. The high latitude/polar ionosphere is sensitive to the perturbation events, as it is intensively connected to the outer space by the geomagnetic field lines. It is perceived that ionospheric variability at low, mid and high latitude is due to variations in the external forces that originate from the thermosphere, the magnetosphere, and the lower atmosphere [D'ujanga et al., 2012, Fayose et al., 2012. Schunk et al., 2002. Apart from latitudinal variation a number of researchers have investigated morphological features of TEC such as the diurnal, monthly, seasonal and solar activity variation using 
various techniques around the globe e.g. in Africa, [D'ujanga et al., 2012, Fayose et al., 2012, Oron et al., 2013, Ouattara and Fleury, 2011, Zoundi et al., 2012] in South East Asia [Walker et al., 1994, in South America [Akala et al., 2013b; de Abreu et al., 2014, Natali and Meza, 2011. Sahai et al., 2007, over China [Liu et al., 2013. Zhao et al., 2007], over North America [Huo et al., 2009, Perevalova et al., 2010], over Japan [Mansoori et al., 2016. Zakharenkova et al., 2012, over Brazil [Venkatesh et al., 2014a, 2014b, 2015 and many more. Ionospheric TEC variations have been investigated in the Indian region also at Surat [Chauhan et al., 2011, Karia and Pathak, 2011], Agra [Nilesh et al., 2017 and many other. The ionospheric plasma density shows significant variations with time, position, geomagnetic and solar activities which can result in a change of most of the ionospheric parameters as total electron content. TEC is expressed in units of TECU ( 1 TECU $=10^{16}$ electrons per square meter), it can be defined as of the total amount of electrons from satellite to receiver path in a single square meter cross-section area.

The total TEC is defined as the total numeral of free electrons along the path of electromagnetic wave from satellite to receiver. Slant TEC or STEC is a measure of the total electron content of the ionosphere along the ray path from the satellite to receiver. It is a quantity that is dependent on the ray path geometry through the ionosphere, whereas the equivalent vertical value of TEC is independent of the elevation of the ray path [Bagiya, 2009].

STEC is converted to VTEC by using the formula:

$$
\mathrm{TEC}=\int_{\text {receiver }}^{\text {satellite }} N d s
$$

where $N$ is electron density [Bagiya, 2009.

$$
\mathrm{VTEC}=\operatorname{STEC} / \mathrm{O}(\Theta)
$$

Two quantities are related by an obliquity factor $\mathrm{O}(\Theta)$, where $\mathrm{O}(\Theta)$ is represented as

$$
\mathrm{O}(\Theta)=\frac{1}{\cos \left[\arcsin \left(\frac{R_{\mathrm{e}} \cos \Theta}{R_{\mathrm{e}}+h i}\right)\right]}
$$

[Liu et al., 2013], where $R_{\mathrm{e}}$ is the mean radius of the Earth and $h_{i}$ is the effective ionospheric height $(400 \mathrm{~km})$. The variation in TEC intensively affects GPS-based communication and navigation system
[Appleton, 1946, Martyn, 1947]. The global positioning system (GPS) signals propagating through the ionosphere are advanced in phase and delayed in time. This time delay being a function of electron density when measured by using dual frequency receiver can compute the TEC. So, the GPS receiver is one of the most useful tools for TEC study [Hofmann-Wellenhof et al., 1992, Langley et al., 2002 .

The TEC in the upper atmosphere plays a crucial role in the determination of the range delays by the electromagnetic signals while traversing through the ionosphere [Rao et al., 2013. In order to study typical ionospheric variations through ionospheric parameters at various latitudes, it is necessary to average these parameters from the available dataset over longitudes or time. This averaging makes it feasible to reveal the meantime and spatial morphological features of global variations in ionosphere [Klimenko et al., 2016]. At the rise of ionospheric studies, there was a thought that diurnal variations in ionospheric parameters everywhere substantially exceed longitudinal variations. However, first satellite data showed that this is not exactly so [Eccles et al., 1971]. It was found that the longitudinal variations of ionospheric parameters are comparable to the diurnal variations. This was further confirmed by many researchers. In the absence of ionospheric TEC data, solar proxies give an opportunity to study ionospheric variation, in the other words, solar proxies show correlation with the variation in ionospheric TEC. This correlation is a part of our study. We have considered solar proxies like $K p$ index, sunspot No, F10.7 index, disturbance storm time (Dst) index. Sunspot No and F10.7 are most commonly used proxies, as they show comparatively better correlation with the variation of ionospheric TEC [Bilitza, 2000. Mansoori et al., 2016. The longest available data series belongs to the sunspot number; it has been regularly recorded for over 400 years. The second largest available data series belongs to F10.7, which has been almost continuously recorded since 1947 [Tapping et al., 2013]. Being most consistent solar index, it effectively describes solar activities and is a valuable mode in forecasting space. F10.7 cm index gives information about the noise level produced by the Sun at the wavelength of F10.7 cm at the Earth's orbit. Sunspots are the area seen as a dark spot on the photosphere. Technically they are concentration of magnetic flux. They are basi- 
cally storm on the surface of the sun; they are the cause of hot gassy ejection and solar flare. Sunspot number $\left(R_{z}\right)$ is the measure of intensity of solar activity. The highest value of $R_{z}$ exhibits solar maxima and the lowest value of $R_{z}$ exhibits solar minima of a solar cycle. They generally appear in defined pattern, they tend to appear on either side of the equator. They start appearing about $25^{\circ}-30^{\circ}$ north and south to the centre, with the progress of solar cycle the new sunspots originate closer to the equator. At the end of solar cycle they normally appear at an average altitude of $5^{\circ}$ to $10^{\circ}$. The generally not appear at the latitude greater than $70^{\circ}$ Prince et al., 2013. Secan et al., 1997.

The change in solar wind directly affects the balance of magnetosphere. The magnetospheric current reacts in order to spare the magnetosphere from collapse; therefore it establishes a new equilibrium state. The changes in different current sheets are measured to estimate the magnetospheric activities. For these measurements magnetic activity indices are used. The ring current or storm activity is usually estimated by using the $D s t$ index and the disturbances in the Earth's magnetic field or global activity measured by $K p$ index. $K p$ index is one of the important scale to study global level of geomagnetic activity. The higher value indicates ionospheric storm which degrades radio propagation. It is a crude measure as it does not measure any specific type of disturbance. It is also defined as global $K p$ index because it characterizes the intensity of geomagnetic activity on a planetary scale [Mukhtarov et al., 2017]. Dst index was developed in 1964 and it defines hourly average of the deviation of Horizontal component of the Earth magnetic field [Sugiura et al., 1964] and measured at several ground stations. It is mentioned in nanotesla (nT). It presents a picture of space weather. It also provides information about the strength of ring current around Earth caused by solar protons and electrons [Saba et al., 1997]. It is a measure of geomagnetic activities, for this purpose $H$ component of geomagnet is recorded periodically at low-latitude. [Bartels et al., 1939]. The value of $D s t$ reflects the intensity of the Geomagnetic storm, the minimum value shows the strongest storm. The negative value of Dst exhibits the beginning of the main face of a storm [Bhattacharya et al., 2008. The storms are categorized as strong storm (peak Dst $<-100 \mathrm{nT}$ ), moderate storms $(-100 \mathrm{nT}<$ peak $D s t<-50 \mathrm{nT})$ and weak storms (peak Dst $>-50 \mathrm{nT}$ ).

This paper is an attempt to study the diurnal variation, monthly variation, annual variation seasonal variation of TEC at low, mid and high latitude in the Northern Hemisphere. The relation between solar proxies (viz. Dst, $K p$ index, F10.7 cm and sunspot number) and ionospheric TEC variation at all the three stations are also included in the paper. The study was carried out during low solar activity period of 24 th solar cycle i.e. from January 2016 to December 2016.

\section{Data Sets and Methodology}

This study was carried out with two type of data sets: Ionospheric data (GPS derived TEC) and geomagnetic indices ( $K p$ index, sunspot No, F10.7 index, Dst index). In present study we considered Universal time (UT) for all time references.

\section{Total Electron Content (TEC)}

To investigate the latitudinal variation of the ionosphere, we considered three IGS stations one at each low, mid and high latitude. The selected locations and their details, including their geographical coordinates, are shown in Table 1.

The data at the three stations were obtained from the network of GPS receivers that are spread over the globe and the data was recorded periodically. The GPS data recorded by IGS is freely available to all the users and can be downloaded from the URL http://sopac.ucsd.edu. This data is available in RINEX (Receiver Independent Exchange Format); it is an internationally accepted data exchange format. This format is in the standard ASCII format (i.e., readable text). The data is then processed by using appropriated tools to get the required (TEC). The temporal resolution of the data is usually $30 \mathrm{~s}$. The dual frequency GPS receivers provide the carrier phase and pseudo-range measurements in two $L$-band frequencies $(L 1=$ $1575.42 \mathrm{MHz}$ and $L 2=1227.60 \mathrm{MHz})$. The TEC is computed from the combined $L 1$ and $L 2$ pseudoranges and carrier phase [Mukhtarov et al., 2017. Further, the raw data is processed by software developed and freely distributed by Dr. Gopi Krishna 
Table 1. The Selected GPS Stations and Their Codes and Coordinates

\begin{tabular}{lcccc}
\hline Sr. No & ID & Location & Geo. Lat. & Geo. Long. \\
\hline 1 & GUUG & Mangilao, US & $13.44^{\circ} \mathrm{N}$ & $144.80^{\circ} \mathrm{E}$ \\
2 & URUM & Urumqi, China & $43.82^{\circ} \mathrm{N}$ & $87.60^{\circ} \mathrm{E}$ \\
3 & NYAL & Ny-Alesund, Norway & $78.92^{\circ} \mathrm{N}$ & $11.86^{\circ} \mathrm{E}$ \\
\hline
\end{tabular}

Seemala, Indian Institute of Geomagnetism (IIG), Navi Mumbai, India. This software runs on a Windows operating system. The raw RINEX GPS data were processed using this GPS TEC analysis software. This software reads raw data, processes cycle slips in-phase data, reads satellite biases from International GNSS Service (IGS) code file (if not available, it calculates them), calculates receiver bias, and calculates the inter-channel biases for different satellites in the receiver.

\section{Geomagnetic Indices}

To study the long-term solar activity we have taken four viz. $K p$ index, sunspot No, F10.7 index, Dst index. We have downloaded the data from Space Physics Data Facility OMNI website (http://omniweb.gsfc.nasa.gov/). We have taken in to account the averages of the downloaded data sets for the study.

\section{Results and Discussion}

The density of ionosphere changes with the season, local time magnetic activity and geographic location. We investigated all the variations at low, mid and high latitudes. At the same time, we also investigated the relationship between ionospheric TEC and solar and magnetic indices viz. $K p$ index, sunspot No, F10.7 cm and Dst index.

\section{Diurnal Variability of TEC}

The variability of TEC for all the days of the year 2016 is presented month-wise in the Figure 1 for low latitude station Mangilao. The multicoloured lines indicate the variation of TEC for all days of each month and the bold yellow line indicates the variation of the median for the month. From the Figure 1, a wider spread of TEC is observed between 00:00 hrs to 14:00 hrs i.e. in the first half of the graph than that of second-half i.e. from 14:00 hrs to 24:00 hrs. We also observed that the maximum average TEC was obtained (highest peak of yellow line) during the months of February, March, April, September, and October, while the shallow peaks were obtained during the month of December, June, July, August, and November. The diurnal pattern of the graphs shows almost similar shape for all the months. The diurnal peak is obtained between approx 08:00 hrs to 12:00 hrs, though peak value changes every month.

The variability of TEC for all the days of the year 2016 is presented month-wise in the Figure 2 for mid-latitude station Urumqi. From the figure, it is observed that from 00:00 hrs to 14:00 hrs i.e. the first half of the graphs show the wider spread in the TEC than that of the second half i.e. from 14:00 hrs to 24:00 hrs. We also observed that the maximum average TEC was obtained (highest peak of yellow line) during the months of February, March, April, May and September, while the shallow peaks were obtained during the month of December, June, July and August. The diurnal pattern of the graphs shows almost similar shape for all the months, though peak value changes every month.

The variability of TEC for all the days of the year 2016 is presented month-wise in Figure 3 for high latitude station $\mathrm{Ny}$-Alesund. We observed that the maximum average TEC obtained (highest peak of yellow line) during the months of February, March, April and September while the shallow peaks were obtained during the month of December, May, June, July and August. The diurnal pattern of the graphs shows almost similar shape for all the months. The diurnal peak occurs between approx 08:00 hrs to 12:00 hrs, though peak value changes every month. 

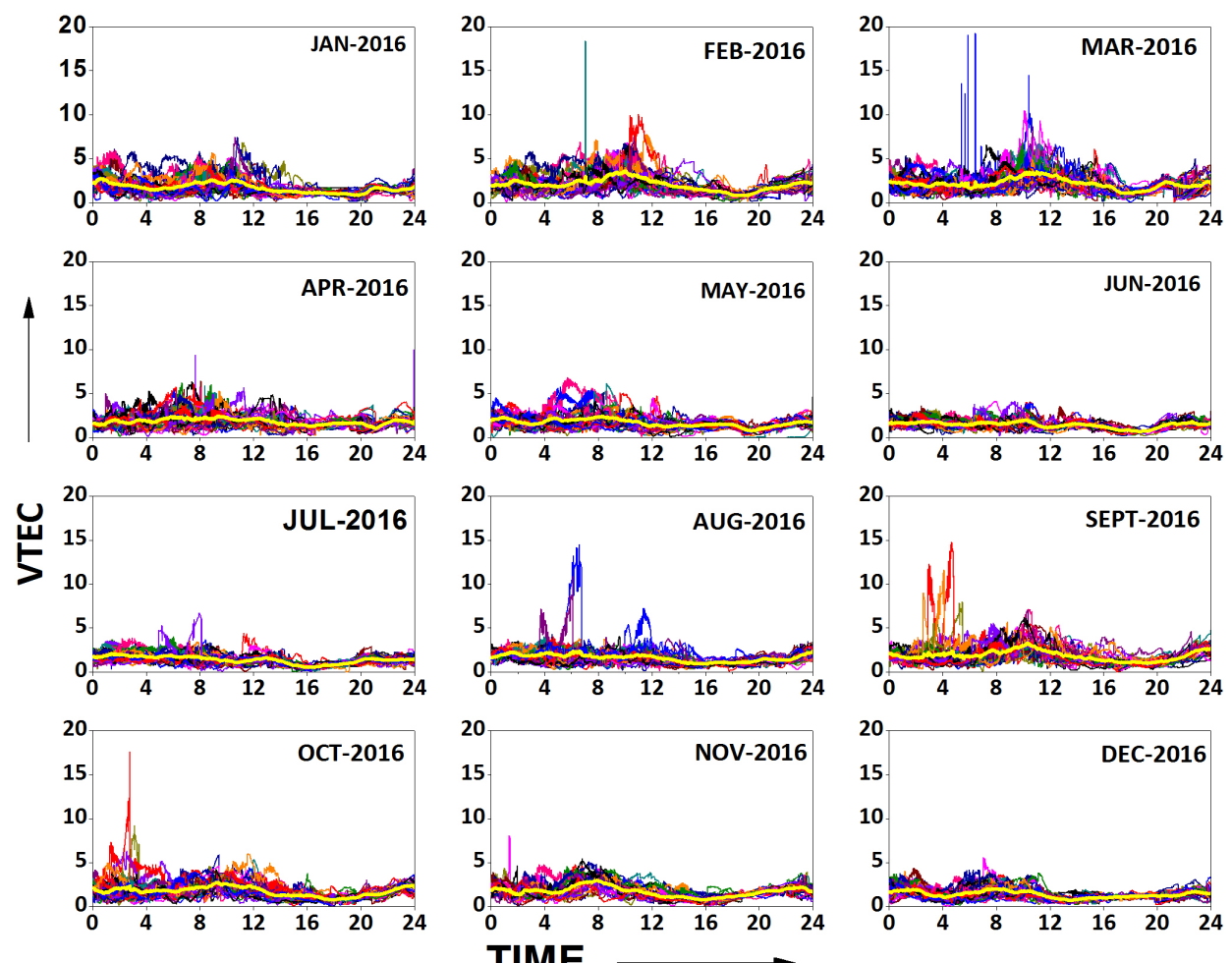

Figure 1. The diurnal variability of the TEC during all the months of the year 2016 at GUUG. UT is considered for time.

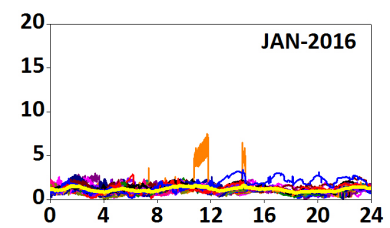

\section{MID LATITUDE-URUM}
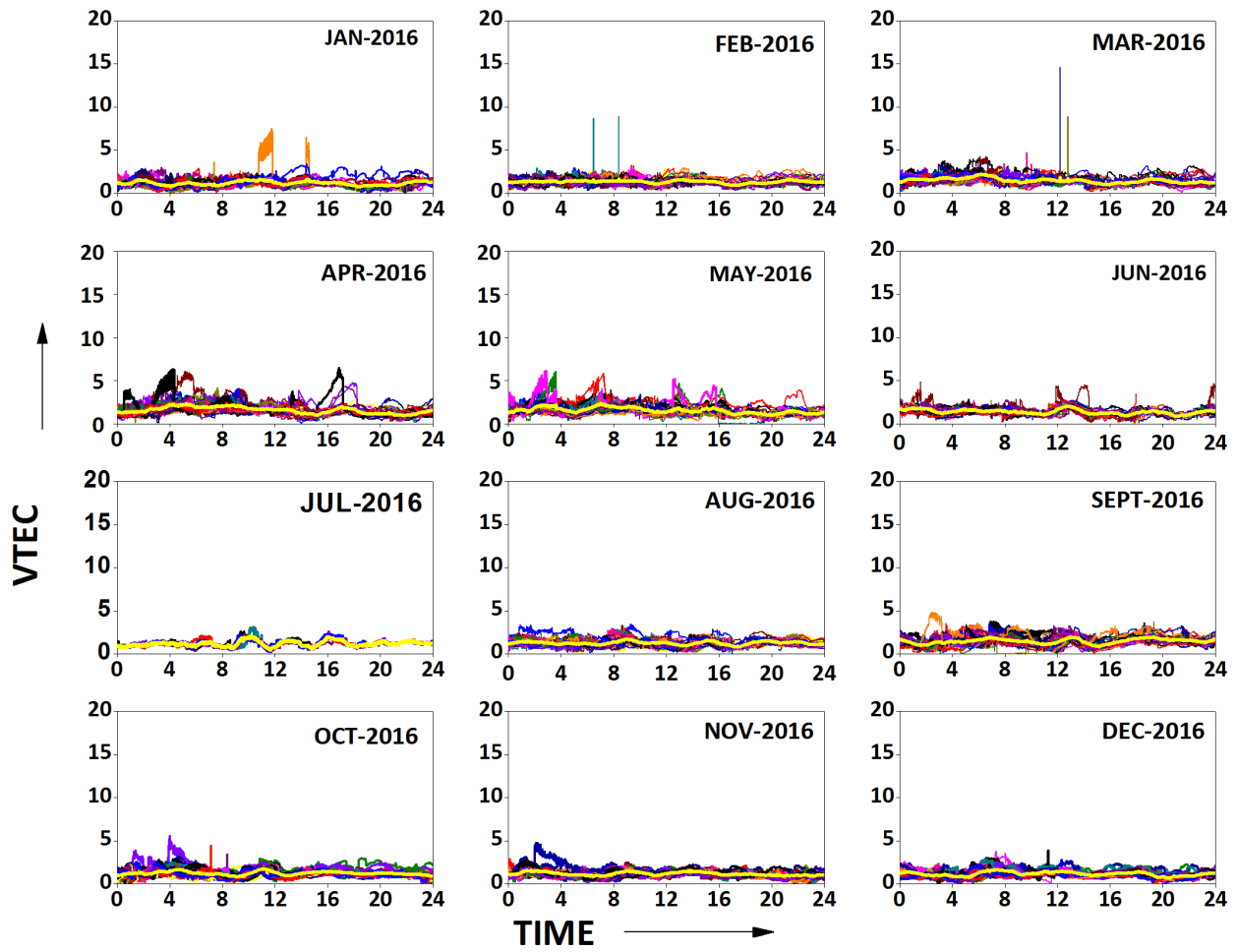

Figure 2. The diurnal variability of the TEC during all the months of the year 2016 at URUM. UT is considered for time. 
HIGH LATITUDE-NYAL
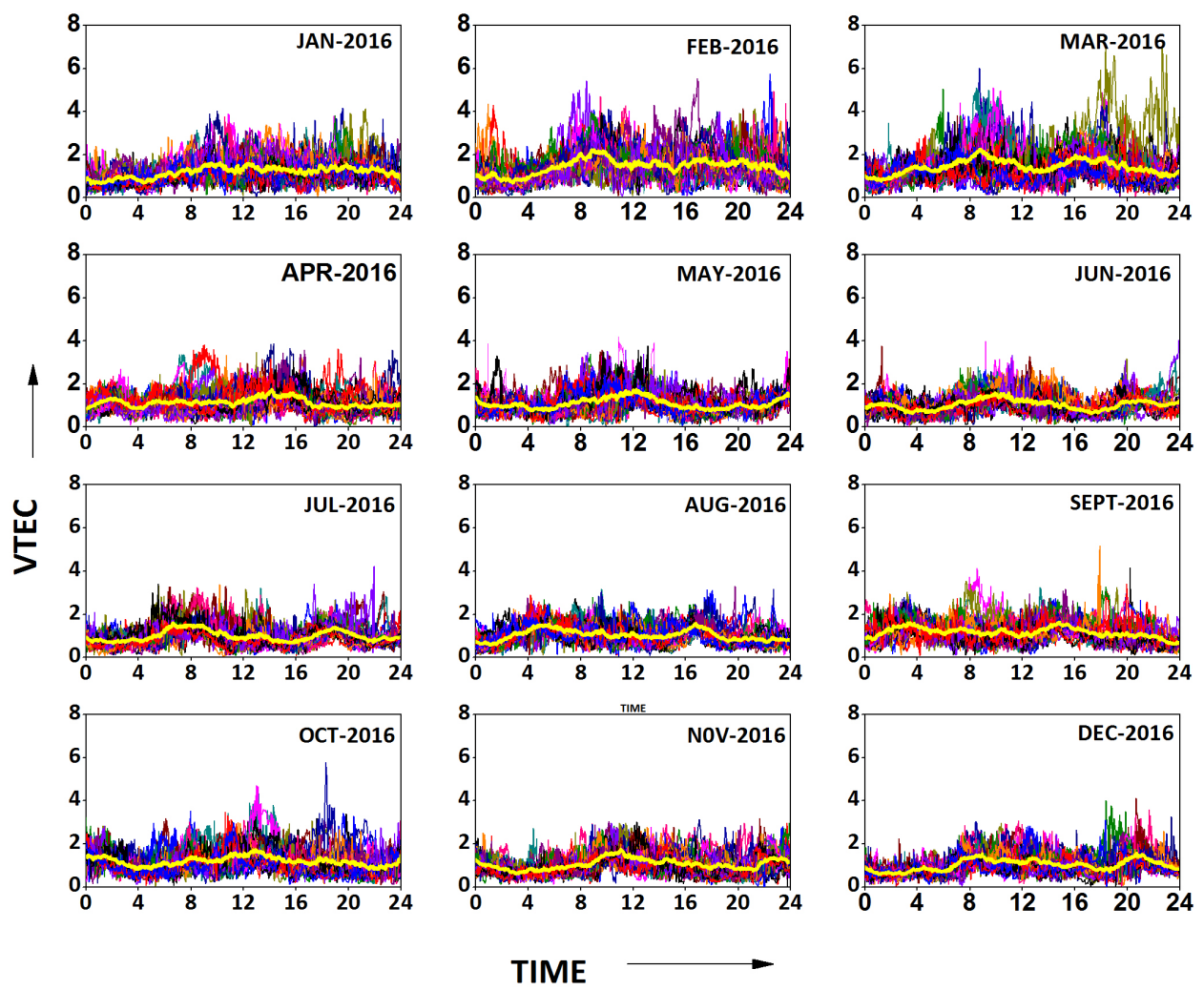

Figure 3. The diurnal variability of the TEC during all the months of the year 2016 at NYAL. UT is considered for time.

Diurnal variation of TEC was also studied by plotting TEC curves for all 366 days at the same graph of the year 2016 at low, mid and high latitude stations. Figure 4 shows the diurnal variation of TEC during the year 2016. The graph is selfexplanatory for the comparison of diurnal variation of the three stations. It is seen that the three curves obtained crest and trough almost during the same period of time, it is also noticed that the rise and fall of TEC follow the similar sinusoidal pattern for the year 2016. Though the magnitude of the TEC is different for the three stations throughout the year, it was also observed from the graph that the maximum TEC value was obtained at low latitude station Mangilao followed by mid-latitude station Urumqi and high latitude station $\mathrm{Ny}$-Alesund. The results confirm that the low latitude region $\left(0^{\circ}\right.$ to $+30^{\circ}$ ) shows higher magnitude TEC as well as higher variation of TEC than that of at mid or high latitude, as this region receives maximum sunlight throughout the year.

\section{Monthly Variability of TEC}

The monthly TEC variation for the year 2016 at mid, low and high latitude stations is presented in Figure 5. The daily average of TEC variation is taken into account to draw the graph. The graph shows that the TEC is maximum during the month of March at low and high latitude and during the month of April at mid-latitude. Whereas the minimum value of TEC is observed during the month of December at low and mid latitude and during the month of July at high latitude.

The monthly TEC data of the three stations also show a sinusoidal pattern that starts rising from January and its peaks are observed in March or April, and then it starts falling gradually and obtains its minimum value in July or August. Further increasing trend is started and the curves obtain their peaks in September or October. Again, the curves lead to its minimal and obtain their bot- 

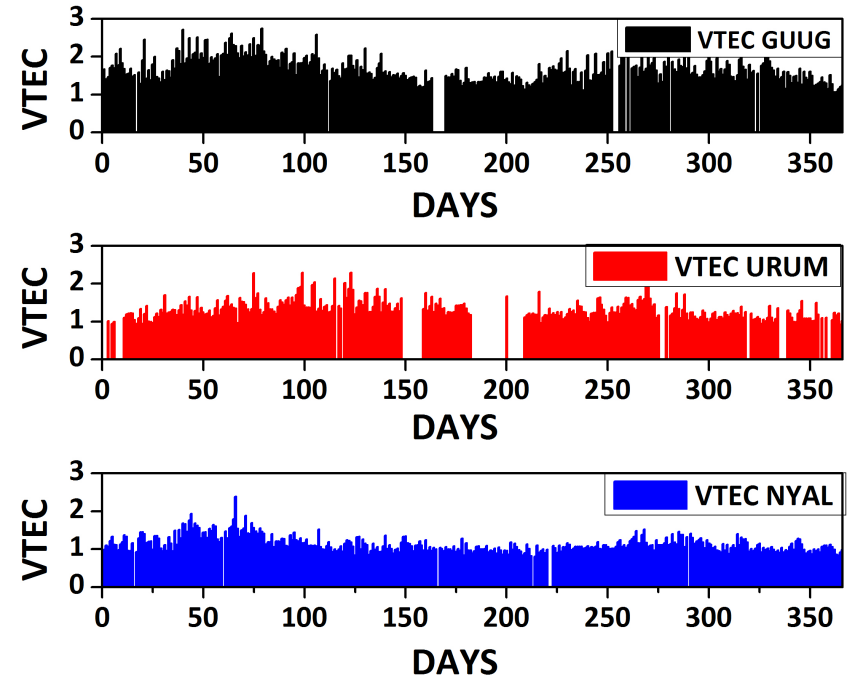

Figure 4. Diurnal variability of TEC during the year 2016 for GUUG, URUM and NYAL stations.

tom value in the month of December. It is significant that both the crests occur during equinox (March and September) and trough occurs during the solstice (June and December). Equinox is the period when the plane of the Earth's equator passes through the centre of the Sun's disk or the Sun is directly over the equator, hence during this period more solar energy is received, which leads to greater ionization. It is also seen that the December solstice shows higher average TEC than that of July solstice, the causative factor of this phenomenon is the Sun-Earth distance between December and June period.

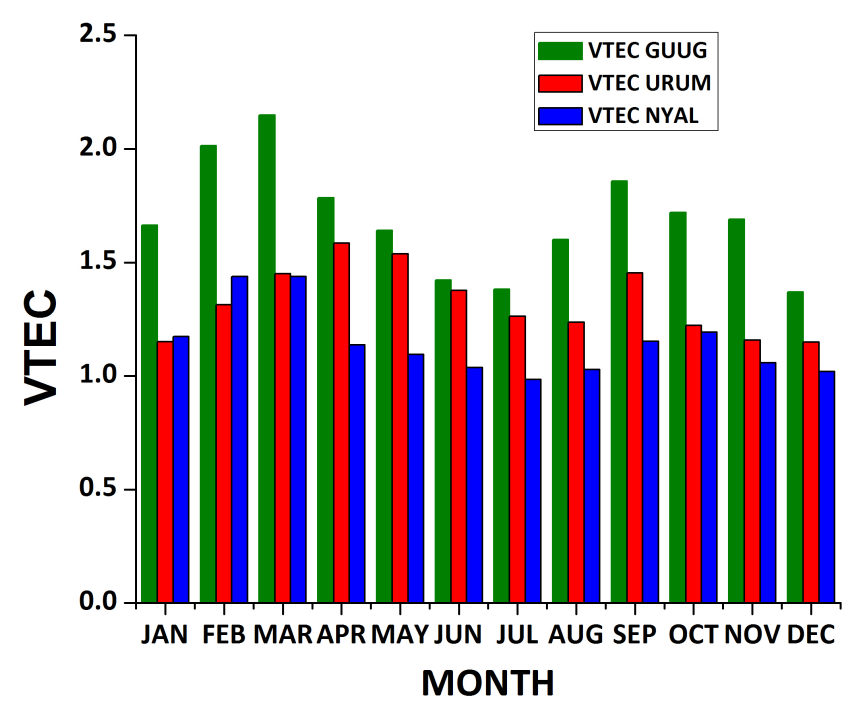

Figure 5. Monthly variability of TEC during the year 2016 for GUUG, URUM and NYAL stations.

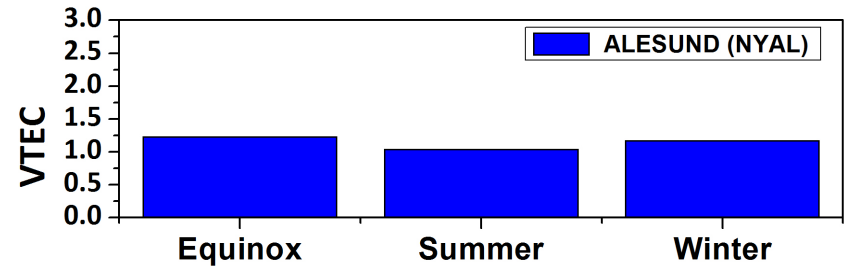

Figure 6. Seasonal variability of TEC during the year 2016 for GUUG, URUM and NYAL stations.

\section{Seasonal Variability of TEC}

The seasonal variations of TEC occur due to tilt in the rotation axis of the Earth and rotation of the Earth around the Sun. This tilt makes the Earth lean towards the Sun (summer) and lean away from the Sun (winter), in between these two seasons equinox occurs. The relative position of the Sun moves from one hemisphere to the other and creates seasons. We have studied the seasonal variability of TEC at low, mid and high latitude stations, during equinox (March, April, September and October), summer (May, June, July and August) and winter seasons (January, February, November and December). The seasonal variation of ionospheric TEC for the year 2016 at the low, mid and high latitude stations is shown in Figure 6 The figure shows that TEC is maximum during the equinox season followed by winter and summer seasons at the high and low latitude and followed by summer and winter seasons at mid-latitude. In other words, it is observed that maximum seasonal TEC is obtained in the equinox months. It is also seen that during the equinox, the maximum value of TEC is obtained at low latitude followed by mid and high latitude. The findings are also supported by the facts that the rate of ionization in equinox is faster than that in winter and summer season which leads to higher TEC at equinox months. Further, during this period, the Sun is directly above the equator which leads to higher value of TEC during equinox at low latitude region than at mid or high latitude.

\section{Geomagnetic and solar Variability of TEC}

Figure 7 shows the variation of VTEC for the different stations and is correlated with F10.7 cm, $K p$ index $D s t$ index. From the graph it is clear that VTEC at low, mid and high latitude in Northern Hemisphere showed a similar annual pat- 


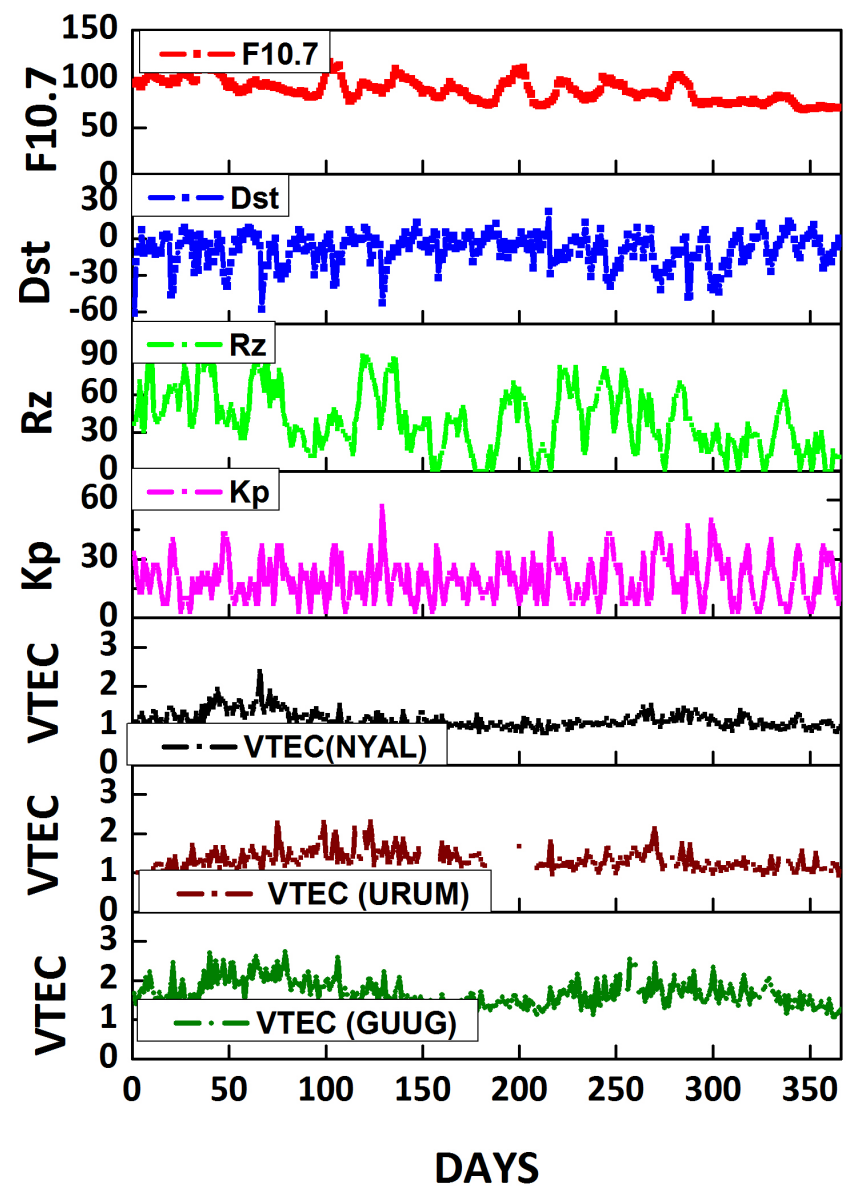

Figure 7. Comparison of variability of TEC with respect to various geomagnetic indices the year 2016.

tern though the magnitude of VTEC was maximum at low latitude followed by mid-latitude and high-latitude. It is observed from the graph that TEC shows better synchronization with $R_{z}$ and F10.7 $\mathrm{cm}$ than with $D s t$ and $K p$ indices. The pattern observed for the ionospheric TEC showed a semi-annual oscillation with maxima in spring and autumn and minima at summer and winter at low, mid and high latitude. This semiannual variation can be satisfactorily explained by Russell-McPherron effect, according to this effect the $B z$ component of geomagnet is enhanced in March (spring) and September (autumn) under southern interplanetary magnetic field (IMF) conditions, as a result, more variation in TEC is obtained during equinoctial months than during solstitial months. The figure shows that the similar semi-annual pattern is also followed by F10.7 and $R_{z}$ index during solar minima 2016.

\section{Variability of TEC During Intense Geomagnetic Storms}

The presence of geomagnetic storm indicates solar wind-magnetospheric interaction. This interaction originates global disturbances in the geomagnetic field as well as in ionospheric TEC. Solar wind is a high energy stream of charged particles (viz. electron, proton, alpha particle etc.) which is ejected from the corona with the speed of 300 to $500 \mathrm{~km} / \mathrm{s}$. We had studied the behaviour of ionospheric TEC during low solar activity period of 24th solar cycle i.e. from January 2016 to December 2016 the geomagnetic storms. During this period we found three moderate storms $(-100 \mathrm{nT}<$ peak Dst $<-50 \mathrm{nT})$. The geomagnetic storms chronologically occur on 1 January 2016 with the daily averaged value of $D s t-61 \mathrm{nT}$, 7 March 2016 with the daily averaged value of Dst -58 nT and 8 May 2016 with the daily averaged value of $D s t$ and $-53 \mathrm{nT}$. We investigated the behaviour of ionospheric TEC at low, mid and high latitude stations viz. Mangilao, US (GUUG) at $13.44^{\circ} \mathrm{N}, 144.80^{\circ} \mathrm{E}$, Urumqi, China (URUM) at $43.82^{\circ} \mathrm{N}, 87.60^{\circ} \mathrm{E}$, and $\mathrm{Ny}$-Alesund, Norway (NYAL) at $78.92^{\circ} \mathrm{N}, 11.86^{\circ} \mathrm{E}$.

The most intense geomagnetic storm of the year 2016 was observed on 1 January 2016. It is observed that the storms that occurred on 1 January, 7 March and 8 May in the same year are having a gradual decreasing intensity with (daily averaged) Dst value $-61 \mathrm{nT},-58 \mathrm{nT}$ and $-53 \mathrm{nT}$ respectively. A similar pattern was observed for F10.7 cm index (gradually decreasing order 95.1, 92.8 and 85.6 respectively). The stations located on low latitudes were affected by the storm more than those stations located on mid and high latitudes.

\section{Conclusions}

The analysis leads to following conclusions

1. It is seen that the maximum diurnal and monthly value of TEC is obtained at low latitude station Mangilao followed by midlatitude station Urumqi and high latitude station Ny-Alesund;

2. It is observed that diurnal TEC shows sinusoidal pattern; 
3. It is seen that seasonal variation of TEC is maximum during the equinox followed by winter and summer seasons at high latitude station and low latitude station and followed by summer and winter seasons at mid-latitude station. In other words, it is observed that maximum seasonal TEC is obtained during the equinox;

4. It is seen that VTEC at low, mid and high latitude of the chosen stations shows similar annual pattern, though the magnitude of VTEC is maximum at low latitude followed by midlatitude and high latitude;

5. The seasonal pattern of ionospheric TEC shows a semiannual oscillation with maxima in spring and autumn and minima at summer and winter;

6. We also compared the annual changes of the TEC with respect to that of the solar proxies viz. $K p$ index, sunspot No, F10.7 index, Dst index. It is seen that the TEC shows a better synchronised variation with $R_{z}$ and $\mathrm{F} 10.7 \mathrm{~cm}$, than that of with $D s t$ and $K p$ indices.

Acknowledgments. The authors are thankful to various online data servers sites like http://omniweb.gsfe. nasa.gov, and http://sopac.ucsd.edu for providing data of different stations. And Dr. Gopi Krishna Seemala, for freely distributing the software to process raw TEC data.

\section{References}

Abdu, M. A., I. S. Batista, G. O. Walker, J. Sobral, N. B. Trivedi, E. R. De Paula (1995), Equatorial ionospheric electric fields during magnetospheric disturbances: Local time / longitude dependences from recent EITS campaigns, J. Atmos. Sol. Terr. Phys., 5\%, No. 10, 1065-1083, Crossref

Akala, A. O., P. H. Doherty, C. S. Carrano, et al. (2012), Impacts of ionospheric scintillations on GPS receivers intended for equatorial aviation applications, Radio Sci., 47, No. 4, 4007, Crossref

Akala, A. O., P. H. Doherty, C. E. Valladares, et al. (2011), Statistics of GPS scintillations over South America at three levels of solar activity, Radio Sci., 46, No. 5, 5018, Crossref

Akala, A. O., E. O. Oyeyemi, E. O. Somoye, et al. (2010), Variability of $f_{o} F 2$ in the African equatorial ionosphere, Adv. Space Res., 45, 1311-1314, Crossref
Akala, A. O., A. B. Rabiu, E. O. Somoye, et al. (2013a), The Response of African equatorial GPSTEC to intense geomagnetic storms during the ascending phase of solar cycle 24, J. Atmos. Sol.-Terr. Phy., 98, 50-62.

Akala, A. O., G. K. Seemala, P. H. Doherty, et al. (2013b), Comparison of Equatorial GPS-TEC Observations over an African Station and an American Station,during the Minimum and Ascending Phases of Solar Cycle 24, Annales Geophysicae, 31, 20852096, Crossref

Appleton, E. V. (1946), Two Anomalies in the Ionosphere, Nature, 15\%, No. 3995, 691, Crossref

Bagiya, M. S. (2009), TEC variations during lowsolar activity period (2005-2007) near the Equatorial Ionospheric Anomaly Crest region in India, Annales Geophysicae, 27, No. 3, 1047-1057.

Bartels, J., N. H. Heck, H. F. Johnston (1939), The three-hour range index measuring geomagnetic activity, Geophysical Research, 44, 411-454, Crossref

Bilitza, D. (2000), The importance of EUV indices for the International Reference Ionosphere, Phys. Chem. Earth, Part C, 25, No. 5-6, 515-521.

Bhattacharya, Soumi, Dubey Smita, Tiwari Rajesh, P. K. Purohit, A. K. Gwal (2008), Effect of Magnetic Activity on Ionospheric Time Delay at Low Latitude, J. Astrophys. Astr., 29, 269-274, Crossref

Chauhan, V., O. P. Singh, B. Singh (2011), Diurnal and Seasonal Variation of GPS-TEC during a Low Activity Period as Observed at A Low Latitude Station Agra, Indian Journal of Radio $\&$ Space Physics, 40, $26-36$.

de Abreu, A. J., P. R. Fagundes, M. Gende, et al. (2014), Investigation of Ionospheric Response to Two Moderate Geomagnetic Storms Using GPS-TEC Measurements in the South American and African Sectors during the Ascending Phase of Solar Cycle 24, Advances in Space Research, 53, 1313-1328, Crossref

D’ujanga, F. M., J. Mubiru, B. F. Twinamasiko, C. Basalirwa, T. J. Ssenyonga (2012), Total Electron Content Variations in Equatorial Anomaly Region, Advances in Space Research, 50, No. 4, 441-449, Crossref

Eccles, D., J. W. King, P. Rothwell (1971), Longitudinal variations of the mid-latitude ionosphere produced by neutral-air winds. II: Comparisons of the calculated variations of electron concentration with data obtained from the Ariel I and Ariel III satellites, J. Atmos. Sol.-Terr. Phys., 33, 371-377, Crossref

Fayose, R. S., R. Babatunde, O. Oladosu, K. Groves (2012), Variation of Total Electron Content and Their Effect on GNSS over Akure, Nigeria, Applied Physics Research, 4, No. 2, Crossref

Hofmann-Wellenhof, B., H. Lichtenegger, J. Collins (1992), Global Positioning System, Theory and Practice. 4th Edition, 389 pp. Springer, Berlin. Crossref 
Huo, X. L., Y. B. Yuan, J. K. Ou, K. F. Zhang, G. J. Bailey (2009), Monitoring the Global-Scale Winter Anomaly of Total Electron Contents Using GPS Data, Earth, Planets and Space, 61, 10191024, Crossref

Jayachandran, B., et al. (1997), Short term ionospheric variability in the northern hemisphere for two consecutive solar cycles, Acta Geod. Geoph. Hung., 32, No. 3-4, 279-285.

Karia, S. P., K. N. Pathak (2011), GPS Based TEC Measurements for a Period August 2008 - December 2009 near the Northern Crest of Indian Equatorial Anomaly Region, Journal of Earth System Science, 120, 851-858, Crossref

Klimenko, M. V., V. V. Klimenko, F. S. Bessarab, I. E. Zakharenkova, A. M. Vesnin, K. G. Ratovsky, I. A. Galkin, Iu. V. Chernyak, Yu. V. Yasyukevich (2016), Diurnal and Longitudinal Variations in the Earth's Ionospherein the Period of Solstice in Conditions of a Deep Minimum of Solar Activity, Kosmicheskie Issledovaniya, 54, No. 1, 10-22.

Langley, R., M. Fedrizzi, E. Paula, M. Santos, A. Komjathy (2002), Mapping the Low Latitude Ionosphere with GPS, GPS World, 13, 41-46.

Liu, G., W. Huang, J. Gong, H. Shen (2013), Seasonal Variability of GPS-VTEC and Model during Low Solar Activity Period (2006-2007) near the Equatorial Ionization Anomaly Crest location in Chinese Zone, Advances in Space Research, 51, 366376, Crossref

Mansoori, A. A., A. K. Parvaiz, A. Rafi, A. Roshni, A. M. Aslam, B. Shivangi, M. Bhupendra, et al. (2016), Evaluation of long term solar activity effects on GPS derived TEC, Journal of Physics: Conference Series, 759, 012069, Crossref

Martyn, D. F. (1947), Atmospheric Tides in the Ionosphere. I. Solar Tides in the F2 Region, Proceedings of the Royal Society of London. Series A, Mathematical and Physical Sciences, 189, 241-260.

Mukhtarov, P., B. Andonov, D. Pancheva (2017), Empirical model of TEC response to geomagnetic and solar forcing over Balkan Peninsula, Journal of Atmospheric and Solar-Terrestrial Physics, XXX, 1-16.

Natali, M. P., A. Meza (2011), Annual and Semiannual Variations of Vertical Total Electron Content during High Solar Activity Based on GPS Observations, Annales Geophysicae, 29, 865-873, Crossref

Nilesh, C. Patel, P. K. Sheetal, N. P. Kamlesh (2017), GPS-TEC Variation during Low to High Solar Activity Period (2010-2014) under the Northern Crest of Indian Equatorial Ionization Anomaly Region, Scientific Research Publising. Positioning, 8, 13-35, Crossref

Oron, S., F. M. D’ujanga, T. J. Senyonga (2013), Ionospheric TEC Variations during the Ascending Solar Activity Phase at an Equatorial Station, Uganda, Indian Journal of Radio \& Space Physics, 42, No. 1, $7-17$.

Ouattara, F., R. Fleury (2011), Variability of CODG TEC and IRI 2001 Total Electron Content
(TEC) during IHY Campaign Period (21 March to 16 April 2008) at Niamey under Different Geomagnetic Activity Conditions, Scientific Research and Essays, 6, No. 17, 3609-3622, Crossref

Perevalova, N. P., A. S. Polyakova, A. V. Zalizovski (2010), Diurnal Variation of the Total Electron Content under Quiet Helio-Geomagnetic Conditions, Journal of Atmospheric and Solar-Terrestrial Physics, 72, 997-1007, Crossref

Prince, Aswathy Mary, Thomas Sanish, Jon Ravi, D. P. Jayapandian (2013), A Study on Midrange Periodicity of Sunspot Number during Solar Cycles 21, 22, 23 \& 24, International Journal of Scientific and Research Publications, 3, $2 . \quad$ (ISSN 22503153)

Rao Rama, P. V. S., K. Venkatesh, D. S. Prasad, K. Niranjan (2013), On the Uncertainties in the Measurement of Absolute (True) TEC over Indian Equatorial and Low Latitude Sectors, Advances in Space Research, 51, 1238-1252, Crossref

Sahai, Y., F. Becker-Guedes, P. R. Fagundes (2007), Response of Nighttime Equatorial and Low Latitude F-Region to the Geomagnetic Storm of August 18, 2003, in the Brazilian Sector, Advances in Space Research, 39, 1325-1334, Crossref

Saba, M. M., et al. (1997), Relationships between the $A E, A p$ and $D s t$ indices near solar minimum (1974) and at solar maximum (1979), Ann. Geophysicae, 15, 1265-1270.

Schunk, R. W., F. A. Nagy (2002), Ionospheres, Cambridge University Press, Cambridge, UK.

Secan, J. A., et al. (1997), Statistical studies of an effective sunspot number, Radio Science, 32, No. 4, 1717-1724, Crossref

Sugiura, M. (1964), Hourly values of equatorial Dst for IGY, Ann. Int. Geophys. Year, 35, 9.

Tapping, K. F. (2013), The $10.7 \mathrm{~cm}$ solar radio flux (F10.7), Space Weather, 11, 394-406, Crossref

Venkatesh, K., P. R. Fagundes, R. de Jesus, et al. (2014a), Assessment of IRI-2012 Profile Parameters by Comparison with the Ones Inferred Using NeQuick2, Ionosonde and FORMOSAT-1 Data during the High Solar Activity over Brazilian Equatorial and Low Latitude Sector, Journal of Atmospheric and Solar-Terrestrial Physics, 121, 10-23, Crossref

Venkatesh, K., P. R. Fagundes, G. K. Seemala, et al. (2014b), On the Performance of the IRI-2012 and NeQuick2 Models during the Increasing Phase of the Unusual 24th Solar Cycle in the Brazilian Equatorial and Low-Latitude Sectors, Journal of Geophysical Research: Space Physics, 119, 5087-5105.

Venkatesh, K., P. R. Fagundes, D. S. V. V. D. Prasad, C. M. Denardini, A. J. de Abreu, R. de Jesus, M. Gende (2015), Day-to-Day Variability of Equatorial Electrojet and Its Role on the Day-to-Day Characteristics of the Equatorial Ionization Anomaly over the Indian and Brazilian Sectors, Journal of Geophysical Research: Space Physics, 120, 9117-9131, Crossref

Walker, G. O., J. H. K. Ma, E. Golton (1994), The 
Equatorial Ionospheric Anomaly in Electron Content from Solar Minimum to Solar Maximum for South East Asia, Annales Geophysicae, 12, 195-209, Crossref

Zakharenkova, I. E., I. V. Cherniak, A. Krankowski, I. I. Shagimuratov (2012), Analysis of Electron Content Variations over Japan during Solar Minimum: Observations and Modeling, Advances in Space Research, 52, 1827-1836, Crossref

Zhao, B., W. Wan, L. Liu, T. Mao, Z. Ren, M. Wang, A. B. Christensen (2007), Features of Annual and Semiannual Variations Derived from the
Global Ionospheric Maps of Total electron Content, Annales Geophysicae, 25, 2513-2527, Crossref

Zoundi, C., F. Ouattara, R. Fleury, et al. (2012), Seasonal TEC Variability in West Africa Equatorial Anomaly Region, European Journal of Scientific Research, 77, 303-313.

Corresponding author:

Shweta Mukherjee, VIT Bhopal Univ., Bhopal-Indore Highway-Kothri-466114, India. (shweta.mukherjee[at] vitbhopal.ac.in) 